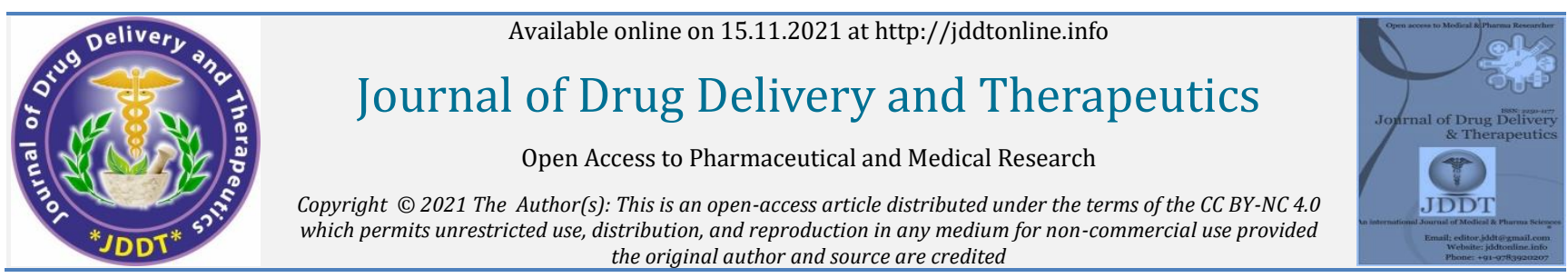
the original author and source are credited

Research Article

Open

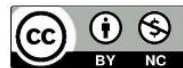

\title{
Formulation and optimization of water soluble granules of Withania Somnifera
}

\author{
Tiwari Dilip Kumar* (D), Mishra Kaushelendra (D), Mishra Neelima (D), Upmanyu Neeraj (D) \\ Lakshmi Narain College of Pharmacy, Bhopal, M.P., India
}

Article Info:

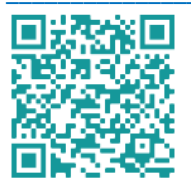

\section{Article History:}

Received 11 September 2021 Reviewed 19 October 2021

Accepted 24 October 2021

Published 15 November 2021

\section{Cite this article as:}

Tiwari DK, Mishra K, Mishra N, Upmanyu N, Formulation and optimization of water soluble granules of Withania Somnifera, Journal of Drug Delivery and Therapeutics. 2021; 11(6):26-30

DOI: http://dx.doi.org/10.22270/jddt.v11i6.5142

\section{Abstract}

Herbal medicines have great demand in the treatment of various kinds of illness. Ayurvedic system of medicine has consisted of many herbal sources in which ashwagandha one of them which are the very popular herbal sources. Many literature surveys suggest that ashwagandha is used as an immunomodulator, tranquilizer, antioxidant, antidiabetic, and nootropic activity. Present research work explored the potential benefit of ashwagandha by designing suitable granules of its water extract. Further, it is characterized by various parameters and In-vitro drug release

Keywords: Immunomodulator, Tranquilizers Ayurvedic, Ashwagandha, Granules

*Address for Correspondence:

Dilip Kumar Tiwari, Lakshmi Narain College of Pharmacy, Bhopal, M.P., India ORCID ID: https://orcid.org/0000-0002-2305-9553

\section{INTRODUCTION:}

Herbal drug treatments and their arrangements have been broadly used historically, for the lots of years in developing and developed nations owing to its herbal origin and lesser aspect outcomes or dissatisfaction with the consequences of synthetic pills. One of the characteristics of oriental herbal medicine arrangements is that all the natural drugs, both presenting as single herbs or as collections of herbs in composite formulae 1 . The traditional arrangements comprise medicinal plant life, minerals, natural be counted, and so forth. Herbal capsules represent in particular the ones traditional drugs which usually use medicinal plant arrangements for therapy ${ }^{2}$ India is referred to as the "Emporium of Medicinal flowers" because of availability of numerous thousands of medicinal plant life inside the oneof-a-kind bioclimatic zones ${ }^{3}$. Medicinal vegetation continues to provide valuable therapeutic retailers, each in contemporary medication and in traditional structures of medicine. Attention is being centered on the research of efficacy of plant based capsules used inside the conventional medication due to the fact they are economy, have a touch facet results and in keeping with WHO, about $80 \%$ of the world populace depend specially on herbal remedies ${ }^{5}$. The World Health Organization has these days defined traditional medication (which include natural capsules) as comprising healing practices that have been in existence, regularly for masses of years, before the improvement and unfold of present day medicinal drug and are nevertheless in use. The points of concept are why not unusual humans divert to apply the Ayurvedic, Chinese and other herbal medicines? Though it's miles used all over the international, in India, its use is much greater due to their clean accessibility, no expert consultation required, are considered safe to use and also due to the fact number one fitness care services fall brief of peoples" want both in qualitative and quantitative phrases. We have to make these kind of without difficulty advertised ayurvedic, and other herbal drug treatments FDA accepted and growth public attention approximately professionals and cons of their makes use of. The common place notion that something herbal is safe isn't accurate.

\section{MATERIALS AND METHODS:}

Roots of withania somnifera collected nearby Bhopal, Petroleum ether, Mayer"s reagent Wagner"s reagent methanol, Sodium Starch glycolate (SSG), Croscarmellose sodium (CCS), and Lactose.

\section{Preparation of extract}

Roots of withania somnifera collected nearby Bhopal shade dried and powdered roots then extracted. For extraction defatted the coarsely powdered drug with petroleum ether by maceration method and then extracted with water. The extract was evaporated above their boiling points. Finally, the percentage yields were calculated of the dried extracts. 
Qualitative phytochemical tests: The extracts obtained by solvent extraction were subjected to various qualitative tests to detect the presence of plant constituents.

Estimation of total phenolic content: Total Phenolic content estimation Principle: The total phenolic content of the extract was determined by the modified Folin-Ciocalteu method.

Preparation of Standard: $50 \mathrm{mg}$ Gallic acid was dissolved in $50 \mathrm{ml}$ methanol; various aliquots of $5-25 \mu \mathrm{g} / \mathrm{ml}$ were prepared in methanol Preparation of Extract: $10 \mathrm{mg}$ extract dissolved in $10 \mathrm{ml}$ methanol and filtered. Two $\mathrm{ml}(1 \mathrm{mg} / \mathrm{ml})$ of this extract was for the estimation of phenol.

Procedure: $2 \mathrm{ml}$ of extract or standard was mixed with $1 \mathrm{ml}$ of Folin-Ciocalteu reagent (previously diluted with distilled water $1: 10 \mathrm{v} / \mathrm{v})$ and $1 \mathrm{ml}(7.5 \mathrm{~g} / \mathrm{l})$ of sodium carbonate. The mixture was vortexed for 15 sec. and allowed to stand for $15 \mathrm{~min}$ for colour development. The absorbance was measured at $765 \mathrm{~nm}$ using a spectrophotometer.

\section{Estimation of total flavonoid content:}

Principle: Determination of total flavonoid content was based on aluminum chloride method
Preparation of standard: $10 \mathrm{mg}$ quercetin was dissolved in $10 \mathrm{ml}$ methanol, and various aliquots of $5-25 \mu \mathrm{g} / \mathrm{ml}$ were prepared in methanol.

Preparation of extract: $10 \mathrm{mg}$ of dried extracted dissolve in $10 \mathrm{ml}$ methanol and filtered. Three $\mathrm{ml}(1 \mathrm{mg} / \mathrm{ml})$ of this extract were taken for the estimation of flavonoid.

Procedure: $1 \mathrm{ml}$ of $2 \% \mathrm{AlCl} 3$ methanolic solution was added to $3 \mathrm{ml}$ of extract or standard and allowed to stand for 15 min at room temperature; absorbance was measured at 420 $\mathrm{nm}$

Preparation of Granules: Granules were prepared by using wet granulation technique. Extract (powder) and citric acid were mixed in a mortar. This was followed by subsequent addition of starch, Sodium Starch glycolate (SSG), Croscarmellose sodium (CCS), and Lactose. Sufficient quantity of distilled water was added to form a lumpy mass which was then passed through sieve no. 22 to form granules. Granules were dried in the hot air oven. Magnesium stearate was added at the end 6 .

Table 1: Composition of fast disintegration granules

\begin{tabular}{|l|l|l|l|l|l|l|l|}
\hline \multirow{2}{*}{ Ingredients } & \multicolumn{7}{|c|}{ Formulation code } \\
\cline { 2 - 8 } & F1 & F2 & F3 & F4 & F5 & F6 & In house Granules*F7 \\
\hline Granules (mg) & 125 & 125 & 125 & 125 & 125 & 125 & 125 \\
\hline Starch (mg) & 50 & 50 & 50 & 50 & 50 & 50 & 50 \\
\hline Sodium Starch glycolate (mg) & 10 & 15 & 20 & - & - & - & - \\
\hline Cross-carmellose sodium (mg) & - & - & - & 10 & 15 & 20 & - \\
\hline Lactose (mg) & 34 & 29 & 24 & 34 & 29 & 24 & 44 \\
\hline Talc (mg) & 5 & 5 & 5 & 5 & 5 & 5 & 5 \\
\hline Magnesium stearate (mg) & 6 & 6 & 6 & 6 & 6 & 6 & 6 \\
\hline Total weight & 230 & 230 & 230 & 230 & 230 & 230 & 230 \\
\hline
\end{tabular}

* In house Granules= without disintegration

\section{Characterization of Herbal granules}

1. Flow property: The angle of repose of powder blend was determined by using funnel method. The accurately weighed $5 \mathrm{gm}$ powder blend was taken in the funnel. The powder blend was allowed to flow through the funnel freely on to the surface ${ }^{7}$. The diameter of the powder cone was measured \& angle of repose was calculated using the following formula:-

Angle of Repose $(\theta)=\tan ^{-1}(\mathrm{~h} / \mathrm{r})$ Where, $\mathrm{h}$ and $\mathrm{r}$ are the height and radius of the powder cone

Further Hausner's Ratio, Compressibility index (Carr's Index) were also determined by using tapped density \& poured density.

Content Uniformity: Granules were $1 \mathrm{gm}$ weighed and then powdered by pestle in a mortar. $100 \mathrm{mg}$ of powdered sample was taken in a beaker containing $20 \mathrm{ml}$ of methanol to dissolve it. The content of the beaker were sonicated for 10 min to extract and dissolve out the flavonoid from granules. The solution was centrifuged at $3000 \mathrm{rpm}$ for $10 \mathrm{~min}$ and the supernatant react with $2 \% \mathrm{AlCl} 3$ and was analyzed after suitable dilution at $420 \mathrm{~nm}$ using UV spectrophotometer.
The mean percent flavonoid content was calculated as an average of three determinations.

In-vitro Disintegration Time: In-vitro disintegration time of formulated herbal granules was determined by using digital disintegration test apparatus. In-vitro disintegration test was carried out at $37 \pm 0.5^{\circ} \mathrm{C}$ in $0.1 \mathrm{~N} \mathrm{HCl}, 10 \mathrm{mg}$ of granules were placed in each of the six tubes of disintegration test apparatus. The time required for complete disintegration of granules in each tube was noted.

In-vitro Drug Release: Study In-vitro dissolution studies of prepared granules were carried out using USP Paddle type dissolution test apparatus. To determine the dissolution, 900 $\mathrm{ml}$ of $0.1 \mathrm{~N}$ HCL was taken as dissolution media and filled in vessel and temperature was maintained at $37 \pm 0.5^{\circ} \mathrm{C}$. Granules were dropped in vessel and paddle was rotated at speed of $50 \mathrm{rpm}$ at $37 \pm 0.5^{\circ} \mathrm{C} .2 \mathrm{ml}$ of samples were withdrawn at suitable time intervals $(1,5,10,15 \mathrm{~min})$ and filtered with pre weighted whatman filter paper. The samples were analyzed using UV spectrophotometer at $\lambda$ max $420 \mathrm{~nm}$ for determination of flavonoid content. Equal amount of fresh dissolution medium was replaced after each withdrawal. 


\section{RESULTS AND DISCUSSION}

Table 2: Result of percentage yield of extract of Withania somnifera

\begin{tabular}{|c|c|c|}
\hline S. No. & Solvents & Percentage Yield \\
\hline $\mathbf{1 .}$ & Aqueous & $4.2 \%$ \\
\hline
\end{tabular}

Table 3: Results of phytochemical screening of aqueous extract of Withania somniferae

\begin{tabular}{|c|c|c|}
\hline S. No. & Constituents & $\begin{array}{c}\text { Aqueous } \\
\text { extract }\end{array}$ \\
\hline $\mathbf{1 .}$ & Alkaloids & - \\
\hline $\mathbf{2 .}$ & Flavonoids & + \\
\hline $\mathbf{3 .}$ & Diterpenes & - \\
\hline $\mathbf{4 .}$ & Phenolics & + \\
\hline $\mathbf{5 .}$ & Amino Acids & + \\
\hline $\mathbf{6 .}$ & Carbohydrate & + \\
\hline $\mathbf{7 .}$ & Proteins & + \\
\hline $\mathbf{8 .}$ & Saponins & \\
\hline $\mathbf{9 .}$ & Glycosides & \\
\hline
\end{tabular}

Presence $=(+)$ absence $=(-)$

Phytochemical analysis of the plant extracts were done to determine the presence of various bioactive constituents according to standard methods. The phytochemical screening revealed the presence of Flavonoids, Diterpenes, Proteins, Amino Acids, Carbohydrate and Saponins compounds in the aqueous extract of roots of Withania somnifera

\section{Total Flavanoid Content estimation (TFC)}

The content of total flavanoid compounds (TFC) content was expressed as $\mathrm{mg} / 100 \mathrm{mg}$ of quercetin equivalent of dry extract sample using the equation obtained from the calibration curve: $\mathbf{Y}=\mathbf{0 . 0 6 X + 0 . 0 1 9 ,} \mathbf{R}^{\mathbf{2}}=\mathbf{0 . 9 9 9}$, where $\mathrm{X}$ is the quercetin equivalent $(\mathrm{QE})$ and $\mathrm{Y}$ is the absorbance.

\section{Calibration Curve of Quercetin}

Table 4: Preparation of calibration curve of Quercetin

\begin{tabular}{|c|c|c|}
\hline S. No. & Conc. $(\mu \mathrm{g} / \mathbf{m l})$ & Absorbance \\
\hline $\mathbf{0}$ & 0 & 0 \\
\hline $\mathbf{1}$ & 5 & 0.352 \\
\hline $\mathbf{2}$ & 10 & 0.61 \\
\hline $\mathbf{3}$ & 15 & 0.917 \\
\hline $\mathbf{4}$ & 20 & 1.215 \\
\hline $\mathbf{5}$ & 25 & 1.521 \\
\hline
\end{tabular}

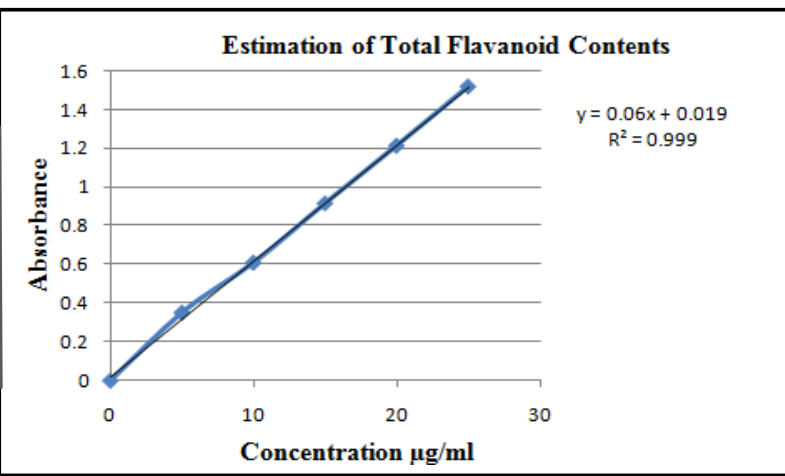

Figure 1: Graph of estimation of total flavanoid content

The flavonoids content was determined by aluminium trichloride method using Quercetin as reference compound. The total flavanoid content in crude extract were evaluated in the present study. The amount of flavanoid present in root of Withania somnifera was 1.010 $\mathrm{mg}$ of $\mathrm{QE} / \mathrm{mg}$ of crude extract.

Table 5: Total flavanoid content of aqueous extract of Withania somnifera

\begin{tabular}{|c|c|}
\hline S. No. & Total flavanoid (QE) (mg/100mg) \\
\hline 1. & 1.010 \\
\hline
\end{tabular}

Table 6: Results of pre-formulation parameters of Herbal granules

\begin{tabular}{|c|l|c|c|c|c|}
\hline \multirow{2}{*}{ Formulationcode } & \multicolumn{5}{|c|}{ Parameters } \\
\cline { 2 - 6 } & $\begin{array}{c}\text { Bulk density } \\
\text { (gm/ml) }\end{array}$ & Tapped density(gm/ml) & Carr's Index (\%) & Hausner'sRatio & Angle ofRepose \\
\hline F1 & $0.38 \pm 0.05$ & $0.45 \pm 0.02$ & $15.556 \pm 0.12$ & $1.184 \pm 0.012$ & $29^{\circ} 25$ \\
\hline F2 & $0.39 \pm 0.01$ & $0.44 \pm 0.03$ & $11.364 \pm 0.15$ & $1.128 \pm 0.011$ & $30^{\circ} 25$ \\
\hline F3 & $0.38 \pm 0.04$ & $0.46 \pm 0.02$ & $17.391 \pm 0.11$ & $1.211 \pm 0.010$ & $29^{\circ} 36$ \\
\hline F4 & $0.39 \pm 0.03$ & $0.45 \pm 0.02$ & $13.333 \pm 0.12$ & $1.154 \pm 0.013$ & $31^{\circ} 26$ \\
\hline F5 & $0.38 \pm 0.02$ & $0.45 \pm 0.02$ & $15.556 \pm 0.11$ & $1.184 \pm 0.014$ & $29^{\circ} 15$ \\
\hline F6 & $0.37 \pm 0.02$ & $0.46 \pm 0.03$ & $19.565 \pm 0.14$ & $1.243 \pm 0.010$ & $29^{\circ} 36$ \\
\hline F7 & $0.38 \pm 0.03$ & $0.46 \pm 0.01$ & $17.391 \pm 0.13$ & $1.211 \pm 0.014$ & $30^{\circ} 36$ \\
\hline
\end{tabular}

Prepared granules of herbal extract shows Carr"s index in the range $11.364 \pm 0.15$ to $17.391 \pm 0.11$, Hausner's ratio in the range of $1.154 \pm 0.013$ to $1.184 \pm 0.012$ and the angle of repose in the range of $29^{\circ} 36$ to $31^{\circ} 26$. The values of these parameter found within the limit which shows good flow property of prepared granules. 


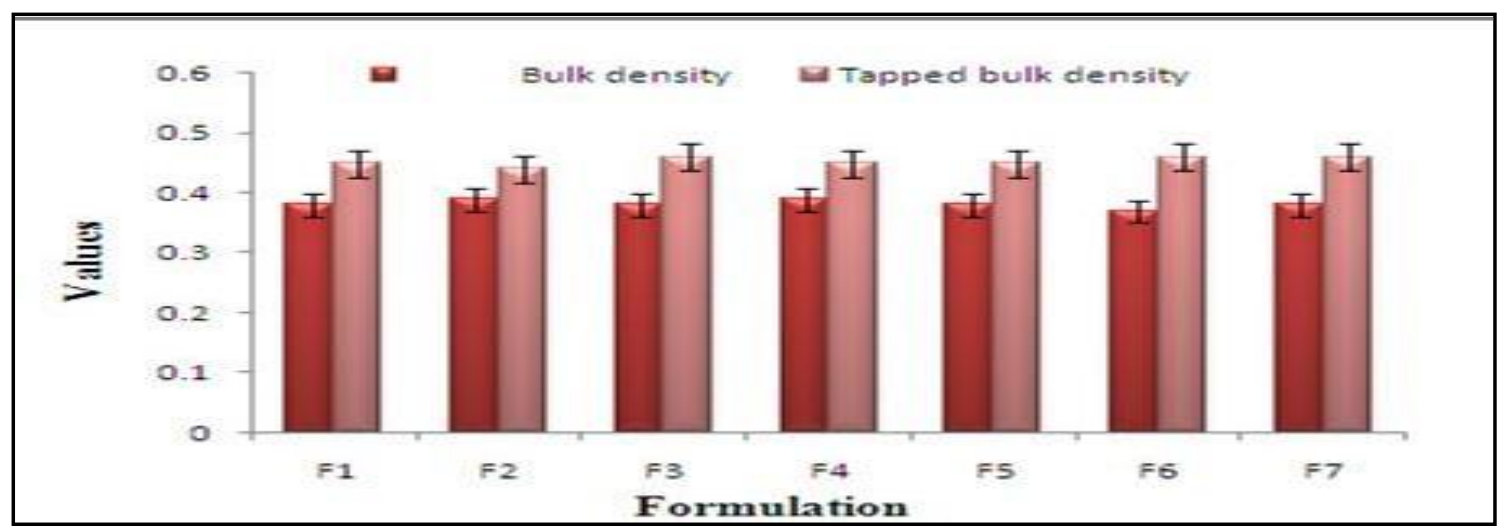

Figure 2: Graph of pre- formulation parameters (Bulk density and Tappeddensity)

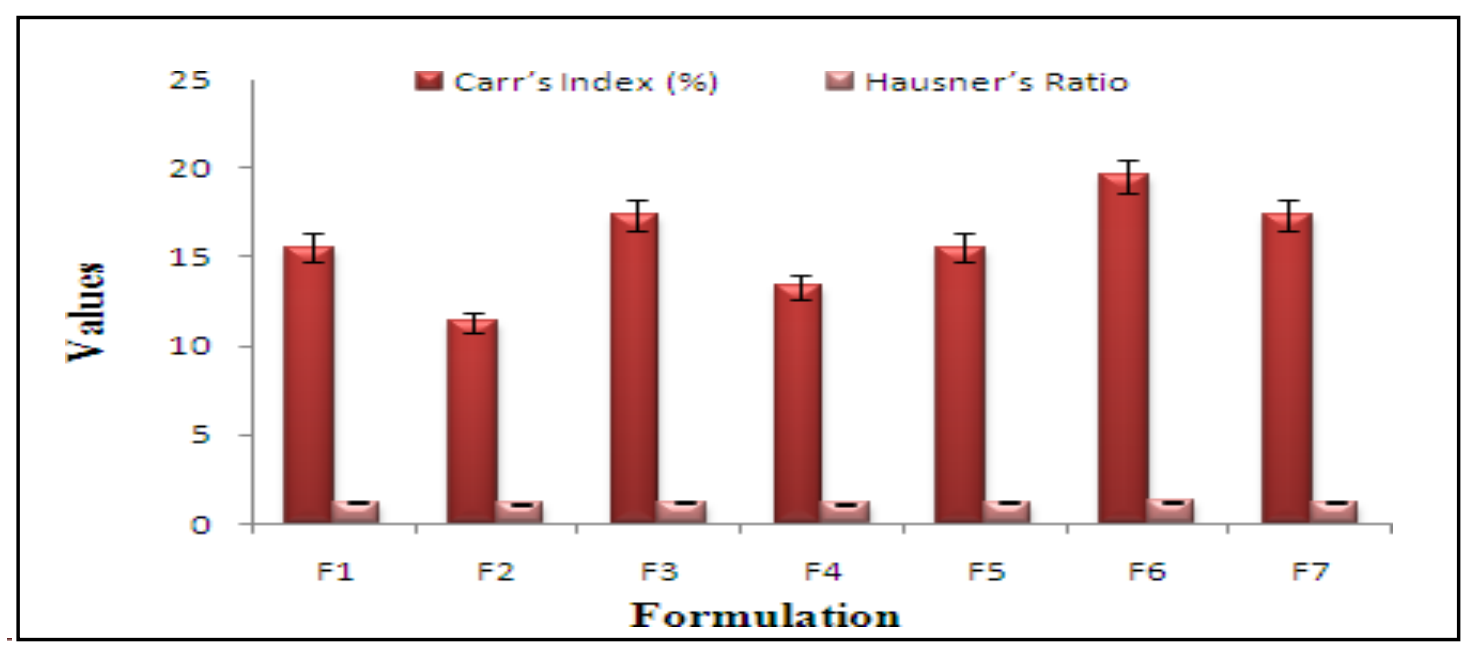

Figure 3: Graph of pre- formulation parameters (Carr's Index and Hausner'sRatio)

Table 7: Results of flavonoid content and in vitro disintegration Time

\begin{tabular}{|c|c|c|}
\hline Formulation Code & Flavonoid content (\%) & $\begin{array}{c}\text { In vitro disintegration time (sec.) } \\
\text { Mean } \pm \text { SD }\end{array}$ \\
\hline F1 & $95.23 \pm 0.11$ & $42 \pm 1$ \\
\hline F2 & $96.56 \pm 0.12$ & $36 \pm 2$ \\
\hline F3 & $95.12 \pm 0.21$ & $32 \pm 1$ \\
\hline F4 & $93.32 \pm 0.32$ & $42 \pm 2$ \\
\hline F5 & $95.54 \pm 0.45$ & $36 \pm 2$ \\
\hline F6 & $96.65 \pm 0.52$ & $30 \pm 2$ \\
\hline F7 & $95.45 \pm 0.12$ & $14.25 \pm 2$ \\
\hline
\end{tabular}

Table 8: In-vitro Drug Release Study

\begin{tabular}{|c|c|c|c|c|c|c|c|}
\hline Time & \multicolumn{7}{|c|}{ \% Drug Release } \\
\hline (Min.) & F1 & F2 & F3 & F4 & F5 & F6 & F7* \\
\hline 1 & 29.98 & 35.65 & 38.45 & 41.56 & 44.45 & 45.65 & 12.25 \\
\hline 2 & 55.65 & 49.39 & 55.65 & 58.98 & 65.58 & 76.69 & 32.25 \\
\hline 5 & 65.65 & 60.45 & 65.48 & 67.98 & 78.98 & 88.98 & 40.25 \\
\hline 15 & 79.98 & 75.65 & 78.98 & 80.25 & 82.26 & 95.65 & 48.98 \\
\hline
\end{tabular}




\section{In vitro drug release study of flavonoid from herbal granules (*without super disintegrants)}

In-vitro release studies of prepared herbal granules were performed in simulated fluid such as simulated gastric fluid $\mathrm{pH}$ 1.2. It was found that release of flavonoid was started after 1 min. The drug release from F1, F2, F3, F4, F5, F6 and F7 was 29.98, 35.65, 38.45, 41.56, 44.45, 45.65 and 12.25 after $1 \mathrm{~min}$. In comparison to all formulation F7 Showed Slowest drug release because of absence of super disintegrants. Formulation F6 showed fastest drug release as compare to other formulation $95.65 \%$ after $15 \mathrm{~min}$.

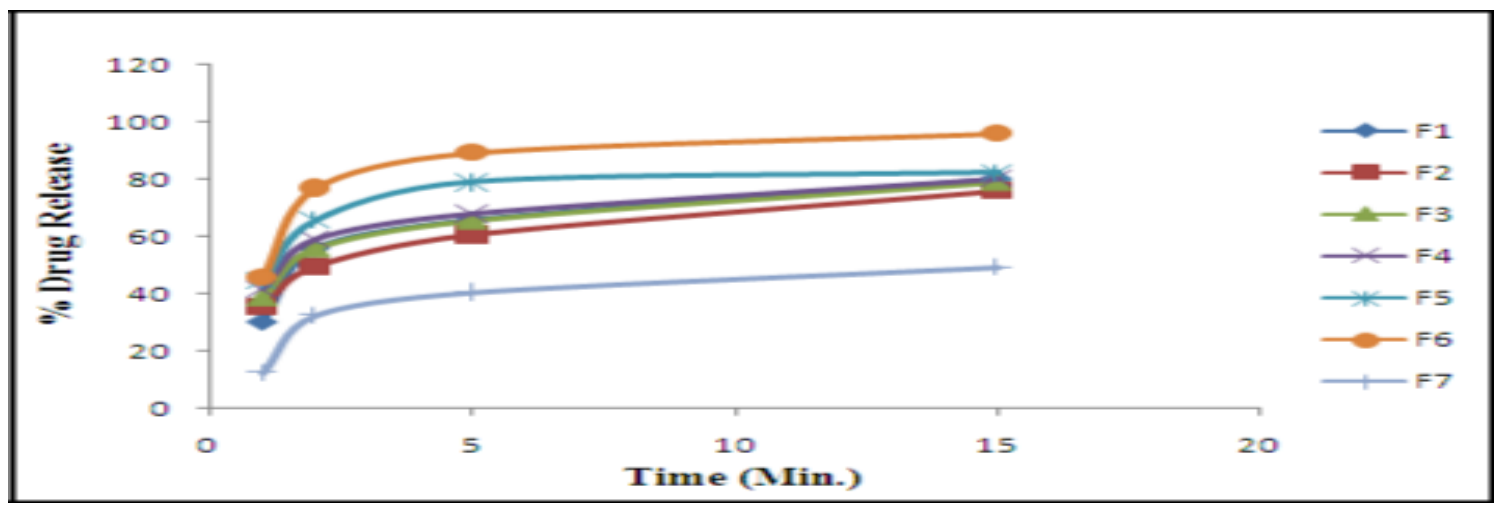

Figure 4: In vitro drug release study of flavonoid from herbal granules

\section{CONCLUSION}

Withania somnifera is considered to be one of the best rejuvenating agents in Ayurveda. Its roots, seeds and leaves are used in Ayurvedic and Unani medicines. Withania somnifera roots find an important place in treatment of rheumatic pain, inflammation of joints, nervous disorders and epilepsy. Dried roots are used as tonic for hiccup, cold, cough, female disorders, as a sedative, in care of senile debility, ulcers, etc. Leaves are applied for carbuncles, inflammation and swellings. Leaf juice is useful in conjunctivitis. Bark decoction is taken for asthma and applied locally to bed sores. Withania somnifera and its extracts are used in preparation of herbal tea, powders, tablets and syrups.

Upon above study we can conclude that designing of dosage form by using super disintegrating agent's changes the release pattern of constituents present in aswagandha extract, and this can helpful in management of dosage protocol and provide better patient compliance. Also this study guides the researcher to how to design the delivery of herbal extracts to get management of dosage regimen.

\section{Acknowledgement}

Author thankful to Lakshmi Narain College of Pharmacy to provide all the facility and support

\section{Conflict of Interest}

The author declares that no conflict of interest

\section{REFERENCES}

1. Balammal G, Sekar BM, Reddy JP. Analysis of Herbal Medicines by Modern Chromatographic Techniques. International Journal of Preclinical and Pharmaceutical Research. 2012; 3(1):50-63. https://doi.org/10.1155/2012/809541

2. Pal KS, Shukla Y. Herbal Medicine: Current Status and the Future. AsianPacific J Cancer Prev. 2003; 4:281-88.

3. Kashaw V, Nema AK, Agarwal A. Hepatoprotective Prospective of Herbal Drugs and Their Vesicular Carriers- A Review. International Journal of Research in Pharmaceutical and Biomedical Sciences. 2011; 2(2):4-9.

4. Prabhu TP, Panneerselvam P, kumar RV, Atlee WC, Subramanian SB. Anti- inflammatory, anti arthritis and analgesic effect of ethanolic extract of whole plant of Merremia emarginata Burm. F. Central European Journal of Experimental Biology. 2012; 1(3):94-99.

5. Patel P, Patel D, Patel N. Experimental investigation of antirheumatoid activity of Pleurotus sajorcaju in adjuvant -induced arthritic rats. Chinese Journal of Natural Medicines. 2012; 10(4):269-74. https://doi.org/10.1016/S1875-5364(12)600545

6. Avalaskar A, Kudale P, Khandelwal P, Natesan S, Shah P, Jadhav R. Formulation and Evaluation of Oral Herbal Granules For Asthma, International Journal of Pharma Sciences and Research. 2016; 7(10):4-10.

7. McKenna A, Mc Cafferty DF, J. Pharm. Pharmacol, 1982; 34(6):347-51. 